\title{
POSSIBILIDADES INTERPRETATIVAS PARA AS PESQUISAS SOBRE INTELECTUAIS NA HISTÓRIA DA EDUCAÇÃO
}

\author{
INTERPRETIVE POSSIBILITIES FOR RESEARCH ABOUT INTELLECTUALS IN \\ THE HISTORY OF EDUCATION
}

AÇÃO INTELECTUAL DE FLORESTAN FERNANDES

FLORESTAN FERNANDES' INTELLECTUAL ACTION

\author{
BORGES NETTO, Mario ${ }^{1}$ \\ MACHADO, Maria Cristina Gomes ${ }^{2}$
}

\begin{abstract}
Resumo
Nesse texto apresentamos uma possibilidade interpretativa para a pesquisa sobre intelectuais na História da Educação. Com base no envolvimento de Florestan Fernandes no debate educacional brasileiro em torno da aprovação da Lei de Diretrizes e Bases da Educação Nacional na década de 1960, analisamos seu posicionamento político a partir da categoria ação intelectual. Como fontes, lançamos mão dos textos educacionais do referido intelectual publicados na imprensa, cujo fim foi se posicionar ante ao dilema e convocar a população nacional para assumir a bandeira da defesa da escola pública. Concluímos que a categoria ação intelectual se torna uma possibilidade para estudiosos que buscam interpretar os posicionamentos dos intelectuais no movimento da história, ou seja, em ação, haja vista que a mesma permite analisar os indivíduos a partir da unidade entre a sua obra e as suas ações políticas sobre o real.
\end{abstract}

Palavras-chave: História da Educação; Ação Intelectual; Florestan Fernandes; LDB $4.024 / 61$.

\footnotetext{
Abstract

In this text we propose to present an interpretative possibility for research about intellectuals in the history of education. From the involvement of Florestan Fernandes in the Brazilian educational debate surrounding the adoption of the Law of Guidelines and Bases of National

${ }^{1}$ Doutor em Educação pela Universidade Estadual de Maringá. Professor Adjunto da Universidade Federal do Tocantins. E-mail: borgesnetto@uft.edu.br

2 Doutora em Educação pela Universidade Estadual de Campinas. Professora Titular do Departamento de Fundamentos da Educação e do Programa de Pós-Graduação em Educação da Universidade Estadual de Maringá. Pesquisadora Produtividade 1C do CNPq. E-mail: mcgm@uem.br
} 
Education in the decade of 1960 , we analyzed his political positioning from the intellectual action category. As sources, we use his educational texts published in the press. The purpose of these texts was to stand before the dilemma and summon the national population to take on the flag of the defense of the public school. We conclude that the intellectual action category becomes a possibility for scholars who seek to understand the positioning of intellectuals in the movement of history. In other words, intellectual action allows analyzing individuals from the unity between their work and their political actions about the real.

Keywords: History of Education; Intellectual Action; Florestan Fernandes; LDB Law $\mathrm{n}^{\circ}$. $4.024 / 61$.

\section{Considerações iniciais}

A história de intelectuais tem ganhado espaço e se tornado objetos relevantes para a História da Educação brasileira. As motivações para isso são diversas, seja pelo que eles representam para a vida social, seja pelas possibilidades temáticas que os estudos sobre intelectuais permitem.

Pensar na figura dos intelectuais, nos conduz ao caminho percorrido por Aristóteles em Metafísica para se chegar a definição de sabedoria. Para conceituá-la, o estagirita, recorre às características do sábio. Seguiremos esse caminho. Para dar contornos ao que seja o intelectual delimitamos as funções sociais que ele exerce. A partir da acepção gramsciana, por intelectuais entendemos os sujeitos sociais que assumem papéis mediadores entre a esfera da produção e o complexo superestrutural (esferas ideológica, cultural, política e jurídica). (GRAMSCI, 2007). São homens da cultura, mas antes de tudo, da política, pois desempenham atividades de direção cultural-ideológica em busca de garantir o consentimento ativo dos indivíduos, e dos grupos sociais, em favor de determinado projeto societário, seja hegemônico ou contra-hegemônico - tenham consciência disso ou não.

Devido à essas tarefas, os intelectuais assumem proeminência no cenário social local, regional, nacional ou universal. Ganham destaque pela força de suas ideias, pelos posicionamentos políticos assumidos publicamente, pela sua capacidade de mobilização da população e/ou por se tornar liderança, dirigente, de determinados grupos sociais. Por isso se tornam importante objeto de estudo para a História da Educação, pois são eles que elaboram interpretações para a realidade e teorizam sobre os diferentes aspectos da vida humana em sociedade. São eles os convocados pela sociedade civil organizada ou pelo Estado para emitir opiniões sobre determinados assuntos e elaborar teorias, projetos, leis e propostas para a vida social e para a educação. 
Das ações sociais exercidas pelos intelectuais na sociedade, tendo em vista sua função cultural e política, emergem variados elementos sociais que podem se constituir em fontes para a História da Educação, são eles: suas biografias, história de vida, formação intelectual e exercício profissional; suas ideias e teorias produzidas em determinado contexto histórico expressas em sua obra; as propostas, os projetos sociais e educacionais que apoiam ou contribuem na elaboração e defesa; os seus posicionamentos políticos (partidários ou não) diante dos problemas sociais do espaço de onde falam, manifestados (na maioria das vezes) em seus textos de imprensa, em palestras e conferências proferidas, em cursos de formação, dentre outras atividades por meio das quais o intelectual manifesta sua postura e finca suas bandeiras no debate.

Do exposto, o que podemos notar é que a História da Educação é tributária das ações dos intelectuais na sociedade, pois, em geral, o campo se debruça sobre as suas ações e seus frutos. A produção do campo em eventos nos permite aferir tal afirmação. Maria Cristina Gomes Machado (2014) apresenta um levantamento sobre a História de intelectuais na educação a partir dos anais das sete primeiras edições do Congresso Brasileiro de História da Educação (CBHE). As nomenclaturas dos Grupos de Trabalhos (GTs) que abrigam os trabalhos sobre a temática em questão sempre relacionam os intelectuais aos outros elementos relacionados à sua função social ou trajetória profissional e acadêmica. No I CBHE, conforme explicita Libânia Nacif Xavier (2001), os trabalhos sobre intelectuais se enquadravam no eixo Pensamento educacional. Os estudos publicados nesse eixo buscavam destacar as trajetórias de intelectuais e os ideários por eles disseminados, articulando pensamento e ação para a partir disso reconstituir o contexto histórico mais amplo. (XAVIER, 2001). No II CBHE, criou-se um novo eixo, Intelectuais e memória da educação brasileira. No III CBHE, o eixo foi excluído, sendo retomado no IV CBHE sob a denominação Intelectuais, Pensamento Social e Educação. No V CBHE, outra alteração. Junto aos intelectuais e pensamento pedagógico, acrescia-se as políticas educacionais. O eixo se tornaria Políticas educacionais, intelectuais da educação e pensamento pedagógico. No VI e VII CBHE, os estudos sobre intelectuais passaram a se relacionar com os impressos, Impressos, Intelectuais e História da Educação.

Podemos notar que os estudos sobre as biografias e história de intelectuais (ou história intelectual) vem ganhando espaço e autonomia no campo da História da Educação. Os estudos de Xavier (2001) e Machado (2014) indicam que ao longo de sete edições do CBHE houve o 
crescimento do número de trabalhos apresentados e publicados em seus anais sobre os intelectuais na (da) educação. O interessante de se notar é que esse crescimento se deu atrelado ao contínuo desenvolvimento dos estudos sobre história do pensamento educacional e das ideias pedagógicas, áreas tradicionais do campo que comportam historicamente inúmeras pesquisas. Em síntese, para reconstruir a história, os pesquisadores recorrem aos intelectuais, às suas ações, ideias e aos seus pensamentos, constituindo-os como emissários privilegiados de um determinado contexto histórico.

Quanto aos estudos sobre intelectuais, segundo Frédérique Matonti e Gisèle Sapiro (2009), podemos dividi-los em dois grupos. Tem-se aqueles estudos acadêmicos que elegem os intelectuais como objeto e modelo de admiração ou rechaço. E outro grupo, seguindo as linhas dos trabalhos de Pierre Bourdieu no campo da história social e da sociologia, que comporta estudos que propõem explicar as tomadas de posição dos intelectuais por meio da relação entre a sua teoria sobre a realidade e a sua posição objetiva no espaço social. Pressupõe-se que a orientação política destas posições, e até mesmo suas formas de se expressar (textos em jornais, conferências, palestras, políticas públicas por eles elaboradas), são explicadas especialmente pela posição de cada um desses intelectuais em sua respectiva área profissional, ou seja, pela sua posição no campo. (MATONTI; SAPIRO, 2009).

Reconhecemos os méritos das diversas formas de se abordar os intelectuais enquanto objetos de pesquisas históricas, contudo, nossa proposta para esse texto é apresentar possibilidades para os estudos que buscam compreender os intelectuais como seres sociais, por isso, históricos, a partir dos seus posicionamentos políticos ante aos problemas sociais aos quais se defrontam. Partimos do fundamento de que a posição política de um intelectual pode ser compreendida objetivamente pela unidade entre a sua teoria sobre a realidade em que atua (a obra) e as suas ações sociais (modo como se posiciona diante do real), o que denominamos de ação intelectual. (BORGES NETTO, 2016). Essa forma de interpretar os intelectuais nos permite considerá-los em movimento, no interior das relações sociais e de classes e nas disputas pela hegemonia. Trata-se de uma possibilidade de pesquisar os esforços políticos dessas personalidades sociais para interferir na realidade em que estão circunscritos, agindo pautados pela forma como interpretam a realidade.

Para exemplificar nossa proposta, utilizaremos dos escritos de Florestan Fernandes sobre o debate educacional acerca da tramitação e aprovação da Lei de Diretrizes e Bases da Educação Nacional (LDB) de 1961. Nas próximas laudas apresentaremos os fundamentos da 
categoria que destacamos, ação intelectual, à medida que analisamos as inserções de Florestan Fernandes no debate educacional brasileiro da década de 1960.

\section{A ação intelectual de Florestan Fernandes ante o debate educacional em torno da LDB 4.024/61}

Quando estudamos a história ou as ideias de um intelectual, procuramos situá-lo no contexto histórico em que ele viveu, produziu suas teorias e agiu nos círculos acadêmicos e políticos. Esse exercício incita-nos a aproximar o intelectual a um grupo social e ao projeto de sociedade a ele vinculado. Em decorrência disso, temos uma tendência a caracterizar os intelectuais de diferentes formas: liberais; positivistas; marxistas; tradicionais; progressistas; reformistas; revolucionários; dentre outras. Entretanto qual parâmetro adequado para entender e caracterizar um intelectual? Seria sua teoria e as respectivas bases epistemológicas? Seria a sua vinculação a grupos diante de um debate político? A orientação dada à sua ação social por meio de um conteúdo programático, estabelecido pelos órgãos de representação de classe?

A nós, o que se destaca é a prática social, que, conforme Karl Marx (MARX; ENGELS, 2007), é o único critério e fundamento da história. Outra orientação importante a esse respeito é dada por Antonio Gramsci (2007). Segundo o autor italiano, em geral, os intelectuais fazem uma leitura equivocada das ações dos homens na realidade, portanto, na história. Lêem e medem os movimentos históricos e políticos com base nas expressões teóricas e literárias, criadas por importantes personalidades, quando deveriam problematizar a ação do intelectual a partir do modo como procura dar respostas às necessidades históricas por meio da arte política, isto é, a partir da capacidade concreta do indivíduo de adequar a ação política enquanto meio à finalidade histórica.

Diante de uma realidade dinâmica, de uma história que não está dada, mas em construção, a ação social e política de um intelectual é circunstanciada pelo jogo político posto, pelas formas como os grupos sociais se articulam na luta de classes. O posicionamento de um intelectual há que ser entendido a partir dessa situação. Logo, cabe problematizar sua inserção no jogo político e a tomada de decisão ante a algum problema social, visto que suas ações podem se dar de modo circunstanciado.

Para os propósitos deste texto, focamos na militância de Florestan Fernandes na luta pela educação pública, na ação prática do intelectual, pois partimos do suposto que é a prática que confere sentido e fundamento às ideias produzidas, e não o contrário. Em vista de 
recuperar o intelectual, suas ideias e ações sociais no contexto vivenciado, privilegiamos, enquanto instrumento analítico, o modo consciente de intervenção do intelectual na realidade, baseado em seu sistema teórico. A isso denominamos de ação intelectual. Adjetivamos o termo ação com a categoria intelectual, pois entendemos que a função social de um intelectual é específica e se difere dos outros sujeitos sociais, qual seja, ser um organizador das massas de homens, um organizador de ideias, um dirigente. (GRAMSCI, 2007). Passamos a entender a ação intelectual como uma prática social consciente e deliberada, por isso uma atividade teórico-prática, adequada a fins de organização ideológico-cultural, cuja implicação é o direcionamento político das condutas de sujeitos individuais de diferentes classes e/ou grupos sociais. Na prática, as ações intelectuais assumem necessariamente caráter classista e sua finalidade pode variar conforme o grupo social com o qual o intelectual está comprometido politicamente, expressando-se de diferentes formas: ação intelectual mantenedora; transformadora ou; na sua radicalidade, revolucionária.

Nesse sentido, a ação de um intelectual deve ser entendida como expressão de uma estratégia política, adotada diante de uma dada circunstância. Por isso, faz-se necessário compreendê-lo como homem de seu tempo, inserido na totalidade, que interfere na realidade e é simultaneamente condicionado por ela. Como os seres humanos não são totalmente livres para agir segundo suas próprias vontades, senão conforme permitem as condições materiais e objetivas do seu tempo (MARX, 2011), os intelectuais, por vezes, são impelidos a adotar estratégias políticas que colidem com a sua visão de mundo e com os seus interesses imediatos. Trata-se de um ser humano cujas ações são condicionadas pela materialidade em que vive, portanto, podem assumir conotações contraditórias. A contradição é própria da vida em sociedade e por isso pode marcar a ação de um intelectual.

É dessa forma que apresentaremos nossas análises sobre o posicionamento de Florestan Fernandes ante o debate educacional em torno da LDB de 1961. Procuramos compreender suas ações na luta pela educação pública como respostas aos problemas sociais brasileiros. Para tanto, com o objetivo de compreendê-lo enquanto intelectual, voltemos as nossas atenções à sua militância na educação, área em que mobilizou seus conhecimentos teóricos para dar respostas às questões que a sociedade demandava, articulando-se com outros intelectuais e negociando posicionamentos e ações em nome de uma bandeira maior, que era a luta pela constituição de uma ordem social democrática no Brasil. 
Neste texto, nos dedicaremos ao envolvimento de Florestan Fernandes com a luta em defesa da educação pública, expressa pela sua participação na Campanha em Defesa da Escola Pública (Campanha). A Campanha foi um movimento em defesa da educação pública no Brasil que mobilizou diversos intelectuais e educadores. "Essa campanha se estruturou formalmente por ocasião da I Convenção Estadual de Defesa da Escola Pública, realizada na cidade de São Paulo em 5 de maio de 1960 [...]”. (FERNANDES, 1963, p.115, nota 7). Foi um movimento em resposta ao debate travado entre os intelectuais brasileiros de diferentes posicionamentos teórico-políticos sobre a reconstrução educacional, em torno das Diretrizes e Bases da Educação Nacional.

Utilizamos como fontes os textos sobre a educação e a escola pública (FERNANDES, 1960a; 1960b; 1966), escritos no calor da militância, os quais revelam seu envolvimento com as lutas sociais do povo brasileiro, expressas nos esforços de Florestan Fernandes pela integração dos grupos sociais desfavorecidos à sociedade e na luta pelos direitos destes enquanto cidadãos. Em última instância, os escritos educacionais expressam o ativismo de Florestan Fernandes, manifesto na luta pela democratização da sociedade para a qual a educação assume papel de destaque. Contudo esses textos não podem ser encarados como panfletários e/ou vazios de conteúdo científico. Ao contrário, devem ser valorizados, pois são reflexões teóricas sobre um problema social, cujos fundamentos estão nas análises sociológicas do intelectual sobre a constituição da sociedade e do capitalismo brasileiro e seus desdobramentos na educação.

A militância de Florestan Fernandes no campo da educação torna-se objeto privilegiado das pesquisas sobre o mesmo, pois as suas ações políticas, que são sociais, por isso práticas, constituem-se como respostas às lutas travadas pelos homens de seu tempo na produção da sua existência. Esse encaminhamento se torna essencial “[...] exatamente quando se trata de um pensador não sistemático, [...] de uma personalidade na qual a atividade teórica e a atividade prática estão entrelaçadas indissoluvelmente, portanto, de um intelecto em contínua criação e num perpétuo movimento 3 ”. (GRAMSCI, 2007, p.419, tradução nossa).

A análise do posicionamento de Florestan Fernandes no debate em defesa da educação pública brasileira com base nesse fundamento permite-nos a compreensão dos condicionamentos históricos e sociais que influenciaram a construção de suas teorias e

\footnotetext{
3 "Questa avvertenza è essenziale appunto quando si tratta di un pensatore non sistematico, quando si tratta di una personalità nella quale l'attività teorica e l'attività pratica sono intrecciate indissolubilmente, di un intelletto pertanto in continua creazione e in perpetuo movimento". (GRAMSCI, 2007, p.419).
} 
condicionaram o seu envolvimento político prático com a realidade. Tomamos como pressuposto a tese marxiana que entende a produção de ideias como imediatamente entrelaçada à atividade material e ao intercâmbio material entre os homens. Os homens, ao produzirem a sua existência, transformam, com esta, sua realidade, seu pensar e os produtos de seu pensar. (MARX; ENGELS, 2007). “Os homens são os produtores de suas representações, de suas ideias e assim por diante, mas os homens reais, ativos, tal como são condicionados por um determinado desenvolvimento de suas forças produtivas e pelo intercâmbio que a ele corresponde". (MARX; ENGELS, 2007, p.93-94). Portanto, não do que os homens dizem, imaginam ou representam, mas do processo de vida real dos homens realmente ativos, do qual se desenvolvem as ideias. Afinal, "[...] não é a consciência que determina a vida, mas a vida que determina a consciência”. (MARX; ENGELS, 2007, p.94).

O envolvimento na Campanha nos permite caracterizar Florestan Fernandes enquanto intelectual orgânico (GRAMSCI, 2007) a serviço da classe trabalhadora. A atividade intelectual, exercida por Florestan Fernandes enquanto docente e pesquisador da Universidade de São Paulo (USP), seria suficiente para caracterizá-lo como intelectual. No entanto, no decorrer de sua vida, Florestan Fernandes tornou-se um intelectual de novo tipo. Não o tradicionalmente reconhecido, cujo modo de ser consiste na eloquência, caracterizado por Gramsci como "puro orador" (GRAMSCI, 2007, p.1551, tradução nossa), mas um “especialista da política”. (GRAMSCI, 2007, p.514, tradução nossa). Um intelectual que se misturou "[...] ativamente com a vida prática, como construtor, organizador, 'persuasor permanente' [...]", que se elevou "[...] da técnica-trabalho [...] à técnica-ciência e à concepção humanística histórica, sem a qual se permanece 'especialista' e não se torna 'dirigente' $(\text { especialista + político })^{4 ”}$. (GRAMSCI, 2007, p.1551, tradução nossa).

O envolvimento de Florestan Fernandes com a luta pela educação articulou simultaneamente as duas características que determinam um intelectual de novo tipo (especialistas e político), que viria a se tornar as principais marcas desse pensador: o sociólogo que procurou servir à busca da verdade por meio científico e o propagandista que buscou convencer os outros cidadãos a verem o que poderiam apreender da realidade e da

\footnotetext{
4 "Il modo di essere del nuovo intellettuale non può piú consistere nell'eloquenza, motrice esteriore e momentanea degli affetti e delle passioni, ma nel mescolarsi ativamente alla vita pratica, come costruttore, organizzatore, <<persuasore permanentemente〉> perchè non puro oratore - e tuttavia superiore allo spirito astratto matematico; dalla tecnica-lavoro giunge alla tecnica-scienza e alla concezione umanistica storica, senza la quale si rimane $<<$ specialista $>>$ e non si diventa $<<$ dirigente $>>$ (specialista+politico)". (GRAMSCI, 2007, p.1551).
} 
ciência para transformar o mundo. Florestan Fernandes foi um intelectual que vislumbrou popularizar uma visão de mundo crítica aos indivíduos dos grupos subalternos, que fosse capaz de criar o terreno adequado para o desenvolvimento de uma vontade coletiva transformadora. O que Florestan Fernandes realizou na Campanha foi algo próximo ao que Gramsci (2007) trata sobre a função dos intelectuais frente à reforma intelectual e moral, o intelectual que se aproxima da massa como contribuição a uma profunda transformação das consciências, iniciativas que não se dão por razões morais, mas de luta política.

No debate educacional, Florestan Fernandes, ao lado de outros intelectuais, buscou provocar o consenso sobre a questão educacional brasileira acerca do Projeto de LDB no debate travado entre defensores da escola pública e privatistas. Na militância pela educação, Florestan Fernandes exerceu as funções de organizador da cultura, de produtor e organizador de ideias, cuja finalidade era direcionar politicamente os brasileiros de diferentes grupos sociais em defesa da escola pública. Trata-se do momento em que o intelectual uspiano colocou o seu conhecimento sociológico e sua disposição militante a serviço das causas educacionais, da educação dos grupos subalternos. Sua militância pela educação ficou registrada na historiografia quando, em $1960^{5}$, na tentativa de conscientizar a população brasileira sobre os problemas educacionais e conquistar o apoio das massas na defesa da educação pública, Florestan Fernandes saiu pelo Brasil em campanha. Percorreu diversas cidades, capitais e interior, proferindo inúmeras palestras e conferências.

A proposta de elaboração da primeira LDB, prevista na Constituição Federal de 1946, adveio da necessidade de consolidar e dar unidade à regulamentação e estruturação da educação no país. Esse empreendimento foi o desdobramento de iniciativas parciais e fragmentadas, iniciadas em 1931-1932 com os decretos do ministro da Educação Francisco Campos, que se estendeu à década de 1940 com a promulgação das Leis Orgânicas do Ensino, formuladas por Gustavo Capanema.

A tramitação do projeto de LDB no Congresso Nacional (1948-1961) gerou um clima inconformista no interior de diversos grupos sociais, que desencadeou várias manifestações por todo o país. O contexto histórico formou um clima favorável à organização dos diferentes grupos sociais que defendiam os princípios democráticos e a educação pública. Por meio das manifestações era propagado o slogan que definiu o caráter do movimento: dinheiro público

\footnotetext{
${ }^{5}$ Os textos sobre a educação brasileira são resultados desse envolvimento na luta pela educação pública. Uma parte expressiva foi produzida no período entre 1959 e 1961 em forma de conferências e palestras ou textos de jornais e revistas. (BORGES NETTO, 2016).
} 
para a escola pública. De acordo com Florestan Fernandes (1966), essas manifestações foram as primeiras iniciativas que conduziram as forças sociais postas em movimento à constituição da Campanha. Essa Campanha aglutinou vários segmentos sociais - estudantes, professores, líderes sindicais, intelectuais e representantes de organizações de várias minorias religiosas, centros culturais e associações operárias - e se tornou um movimento cívico, que propunha a defesa da herança republicana e da filosofia democrática da educação.

$\mathrm{Na}$ historiografia brasileira é unânime a constatação do envolvimento de Florestan Fernandes com o debate educacional. Dermeval Saviani (1996) e Ester Buffa (1979) afirmam que, a partir da década de 1950, Florestan Fernandes assumiu a postura de militante e divulgador da bandeira da democratização da educação no Brasil e tornou-se "[...] o batalhador incansável na luta pela escola pública, proferindo inúmeras conferências e publicando vários estudos”. (BUFFA, 1979, p.63).

$\mathrm{Na}$ Campanha, Florestan Fernandes lutou ao lado de um volumoso grupo de liberais e se posicionou de forma intransigente em defesa da educação pública contra os ataques proferidos pelos representantes da Igreja Católica e dos empresários da educação. A origem humilde de Florestan Fernandes, as condições materiais e objetivas por ele vividas o fizeram um defensor e representante dos interesses das camadas populares. A sua consciência de classe, forjada desde a sua infância pobre, impôs a Florestan Fernandes a necessidade de se tornar um militante e intelectual dos desfavorecidos. O terreno político-ideológico, criado pelo debate sobre o projeto de LDB, não foi somente um importante espaço de formação, senão um lócus privilegiado da sua atuação política e intelectual.

Os grupos idealizadores da Campanha centravam em suas ações políticas e publicistas dois encaminhamentos: 1) o objetivo central era a defesa intransigente da qualidade e eficácia do ensino e 2) impedir que o Estado democrático se tornasse prisioneiro de interesses particularistas dos empresários da educação e da Igreja católica, que passavam pela garantia da liberdade de ensino e pela canalização de recursos públicos para as escolas privadas.

Os intelectuais envolvidos com a Campanha entendiam que, num país subdesenvolvido e dotado de recursos escassos para a educação, a luta pela qualidade da educação passaria necessariamente pela defesa da escola pública, pois somente por meio dela se tornaria viável oferecer condições de produzir um bom ensino e proporcioná-lo, sem restrições econômicas, raciais, sociais ou religiosas, a qualquer indivíduo. Consequentemente, defendiam a autonomia do Estado democrático na realização das tarefas educacionais, pois, 
diante dos graves problemas educacionais brasileiros, julgavam que os esforços estatais deveriam se concentrar nas escolas criadas e mantidas por sua iniciativa. Isso requeria maior investimento no sistema de ensino público, que carecia de melhorias e expansão. Dessa forma, eram veementemente contrários à subvenção das escolas privadas pelo Estado, porém não se opunham às suas existências. Esse posicionamento pode ser verificado nas palavras de Florestan Fernandes:

A dispersão dos recursos oficiais, destinados à educação, vai prejudicar frontalmente e em conjunto tôdas as medidas de democratização do ensino que se impõem! Dado o volume de responsabilidades educacionais do Estado e a escassez de meios para atende-las, essa dispersão nos levará a algo que só pode ser definido como devastação pura e simples dos recursos públicos de forma improdutiva ou semiprodutiva. Doutro lado, além de servir diretamente a interêsses imediatistas dos proprietários de escolas particulares, vai tornar impossível uma intervenção maior do Estado na distribuição das oportunidades educacionais em bases justas ou equitativas. Como demonstrou Almeida Júnior, as bôlsas destinadas a pagamentos de anuidades escolares irão beneficiar camadas da população brasileira que podem custear a educação dos imaturos. A alternativa que se impunha, para beneficiar os setores menos privilegiados da sociedade brasileira, seria a concessão de bôlsas a alunos pobres - não para pagar anuidades, mas para permitir a frequiência à escola pública gratuita. O subaproveitamento das oportunidades educacionais no Brasil resulta do nível de pobreza da maioria da população, que está em condições econômicas sequer de aproveitar a escola pública gratuita onde ela exista. Essa alternativa se chocava, porém, com os interêsses egoísticos dos grupos de pressão, que exerceram influências na confecção do projeto de lei e, por isso, não foi considerada. Ela parece ser, não obstante, uma das vias para as quais precisaremos apelar, para promover o desenvolvimento educacionais nos setores pobres da população brasileira, em particular nas regiões menos prósperas do País. (FERNANDES, 1960a, p.163-164).

O que notamos no posicionamento e nos encaminhamentos dos defensores da educação pública é a crítica moral ao Estado e a reivindicação por coerência, que as iniciativas estatais fossem capazes de adequar a formação do homem brasileiro à ordem social republicana e democrática. Florestan Fernandes era categórico no seu posicionamento. Considerava que os legisladores, que diziam ser preocupados com os ideais da democracia ou do regime republicano-democrático, não deveriam ter alternativa senão defender uma política educacional que fortalecesse a escola pública e a expansão do sistema público de ensino. (FERNANDES, 1960a). Para o intelectual, somente por meio da escola pública o Estado seria capaz de realizar plenamente sua tarefa educacional de formar o cidadão brasileiro. 
Só esta escola oferece ao Estado as perspectivas e as condições para a plena realização de suas tarefas educacionais, para o recurso crescente ao planejamento educacional, para fiscalização dos fatôres extra-educacionais que interferem no processo educativo e para o aproveitamento progressivo das aptidões dos educandos. Além disso a escola pública não seleciona sua clientela seguindo critérios econômicos, étnicos ou ideológicos. Por natureza, é aberta a todos os candidatos aptos a receber instrução, a todo o progresso do conhecimento científico e a tôda tentativa de ampliar o horizonte intelectual do homem, especialmente no que concerne à participação responsável na vida coletiva. (FERNANDES, 1960a, p.164$165)$.

Diante do cenário educacional, a defesa da educação pública, manifestada pela Campanha, para além da luta pela democratização da educação e da qualidade do ensino, foi tratada por Florestan Fernandes como um processo de conscientização da população brasileira sobre os magnos problemas do país, dentre eles, a educação como privilégio. Foi um período de intensa ação publicista, cujos objetivos seriam esclarecer e alertar todos os brasileiros para que se preocupassem com os problemas educacionais. O sociólogo entendia que todos os cidadãos, independentemente do seu saber ou prestígio, deveriam colocar-se na condição “[...] de influenciar, pelos mecanismos normais do regime democrático, as decisões e orientações dos partidos e do govêrno nesse campo". (FERNANDES, 1960b, p.186). Sua avaliação era de que a baixa qualidade da educação pública no Brasil, os ataques direcionados a ela e os rumos que ela poderia assumir eram resultantes do baixo ou pouco interesse da população em defendê-la e dirigi-la.

A "má escola" é produto direto do desinterêsse dos usuários dos serviços educacionais por seu funcionamento, destino e rendimento. A "má aplicação" dos fundos educacionais e a "má política educacional" também são frutos diretos da indiferença da coletividade às iniciativas oficiais no terreno da instrução pública. O progresso educacional, base e condição de qualquer outra espécie de progresso (econômico, político ou social), depende de uma participação ativa consciente e altruísta de todos os cidadãos na melhor utilização dos recursos educacionais disponíveis. Essa participação numa sociedade de massas e de organização democrática, afeta tanto os que "conhecem" os problemas educacionais, quanto os que "nada sabem" a seu respeito. Por isso, visamos deliberadamente a incluir os problemas educacionais brasileiros dentro do horizonte intelectual do cidadão comum, com fito de torná-lo um colaborador constante, construtivo e vigilante do nosso progresso educacional. (FERNANDES, 1960b, p.186-187).

Mesmo atribuindo responsabilidade e peso às ações políticas da população, Florestan Fernandes tinha consciência do papel que os intelectuais deveriam assumir diante dos problemas nacionais. Considerava que as obrigações práticas dos sociólogos não se 
distinguiam tanto das obrigações que o restante da população deveria assumir, senão na sua magnitude, pois eram cientistas e por isso deveriam ser aqueles capazes de enxergar melhor os problemas sociais. Diante dessa capacidade, os sociólogos deveriam assumir a responsabilidade de intelectual e evidenciar o problema, incentivar o interesse da população em resolvê-lo e os comportamentos que responderiam positivamente às exigências da situação. Florestan Fernandes (1963), concebia que os sociólogos deveriam assumir o papel de vanguarda na conscientização dos problemas sociais, não podendo abrir mão desse pesado fardo, mesmo sob o sacrifício de alguns projetos de estudos pessoais.

Para Florestan Fernandes, os cientistas sociais precisariam empenhar-se diretamente no processo de mudança social pelo qual o país passava, centrando seus esforços na democratização da sociedade brasileira e no direcionamento do país à nova ordem social, democrática, urbana e industrial.

Acredito que exista amplo ensejo para opiniões divergentes, no que concerne à valorização sociológica dos focos centrais de mudança da situação histórico-social. Ainda assim, mais para completar a presente discussão, gostaria de enumerar três áreas que, no meu entender, encerram potencialidades dinâmicas que não devem ser negligenciadas nas reflexões práticas dos cientistas sociais brasileiros. Refiro-me à [1] expansão da ordem social democrática, às [2] funções sociais construtivas do Estado e às [3] opções espontâneas que decidirão, socialmente, como iremos participar da "civilização da era industrial e tecnológica" no Brasil. (FERNANDES, 1963, p.84-85).

Dos encaminhamentos de Florestan Fernandes aos sociólogos, entendemos que se envolver com as mudanças sociais em curso no Brasil era se envolver com a luta em defesa da educação pública, elemento necessário para a consolidação da ordem social democrática. Para o intelectual, os males que a sociedade brasileira precisava combater eram por demais arraigados e por isso "[...] só desaparecerão mediante uma alteração profunda da mentalidade média do homem brasileiro". (FERNANDES, 1966, p.348). Disso concluímos que o modo como Florestan Fernandes analisou a educação brasileira e se envolveu politicamente com ela foi a manifestação prática de seus estudos sociológicos sobre a constituição da sociedade brasileira e da forma dependente do seu capitalismo.

Na obra de Florestan Fernandes, a educação é entendida tanto como uma necessidade da vida social moderna, quanto como um fator de alteração da ordem social, um fator social construtivo. A formação e o desenvolvimento da economia capitalista, da democracia e da sociedade de classes elevariam o grau de importância do elemento cultural, no que se referia 
ao direcionamento do comportamento dos cidadãos frente às necessidades sociais, baseado na consciência e na escolha racionais de fins e meios. A sociedade moderna se fundamenta na secularização e racionalização da vida social, por isso a democratização da cultura se tornou um requisito intelectual da vida prática e conferiu à educação funções socializadoras, relacionadas a todas as atividades sociais fundamentais da civilização industrial e urbana. (FERNANDES, 1971). Nesse contexto a educação deveria assumir funções sociais capazes de consagrar

[1] a igualdade fundamental de todos os indivíduos; [2] idênticas oportunidades mínimas de preparação para a vida, como requisito para a plena fruição dos direitos sociais e a aceitação responsável dos deveres correlatos; [3] e o acesso, apenas restringido pelas disposições ou capacidades pessoais, às diferentes posições sociais com as probabilidades correspondentes de segurança, de prestígio e de poder. (FERNANDES, 1971, p.182-183).

No Brasil, a educação não havia assumido tais funções e se tornou um elemento de demora cultural, pois não correspondeu às necessidades históricas do contexto, configurandose como um privilégio social dos grupos sociais hegemônicos. Tais grupos controlavam e organizavam a educação para a manutenção do status quo, do qual eram beneficiários. O que percebemos disso, segundo Florestan Fernandes (1971), é que a educação não era, ou pouco era, utilizada deliberadamente como instrumento de intervenção racional na vida prática. A despeito do valor social que a educação assumiu no país desde a transição do Império para a República, os seus impactos na constituição da nova ordem social (livre e competitiva de aspiração democrática) foram insatisfatórios e insuficientes. Para o intelectual, a educação se prendia a valores obsoletos que pouco contribuíam para a preparação dos indivíduos para a vida em uma sociedade capitalista. De acordo com Florestan Fernandes (1971), esse descompasso entre a educação e as necessidades da sociedade capitalista ocorreu porque o controle das instituições sociais estava nas mãos dos grupos sociais hegemônicos, que as controlavam segundo os interesses dos indivíduos, grupos e famílias que possuíam riqueza, prestígio e poder. Na sociedade de classes, de capitalismo dependente, os interesses privados controlavam as instituições sociais e suas atividades. Contudo transformar a realidade não era inviável, defende o sociólogo.

Partimos do suposto de que a história é construída pelos homens, portanto, somente eles podem interferir no seu curso, seja para a manutenção ou alteração. As mudanças sociais podem ser provocadas, induzidas e planejadas. Pensar na indução das mudanças sociais é 
pensar em um projeto de formação humana do presente para o futuro. Sem perder a materialidade do processo, considerando a transição vivida pelo Brasil de uma ordem social para outra, era necessário intervir na personalidade e preparar os homens recém-egressos da ordem social tradicional para enfrentar os problemas práticos, próprios da ordem social livre competitiva. Entram em cena os questionamentos sobre os requisitos intelectuais, requeridos para a vida social, em que prevalecem os modelos racionais de pensamento e a ética baseada na concepção científica do mundo. A partir dessa concepção, a educação

[...] deixou de ser concebida como fim em si mesmo, como regalia ou como valor supremo, para ser relacionada com as necessidades fundamentais da vida e com os modos inteligentes de satisfazê-las, que parecem assegurar continuidade ao progresso do nosso sistema civilizatório. Em última instância, ela tende a converter-se, no clima moral produzido pelo pensamento científico, em um dos fatôres racionais de contrôle dos elementos naturais e artificiais do ambiente pelo homem. (FERNANDES, 1971, p.191-192).

Nessa perspectiva, a educação deveria ser capaz de desenvolver nos cidadãos conhecimentos e capacidades que favorecessem seus ajustamentos ativos às condições de mudanças com que a sociedade se defrontava. Sobre isso, Florestan Fernandes considera que “[...] não se trata, apenas, de formar a personalidade para as condições atuais de existência. Porém, de criar personalidades aptas a enfrentar, criticamente, as exigências do presente e resolvê-las em têrmos de soluções válidas para o futuro". (FERNANDES, 1971, p.147).

Do ponto de vista sociológico, para Florestan Fernandes (2008), a questão educacional deveria extrapolar os problemas referentes aos aspectos didático-pedagógicos e ao rendimento escolar, fosse institucional, fosse dos alunos. Deveria ser muito mais ampla e preparar os jovens para se ajustarem a papéis sociais e políticos na sociedade brasileira enquanto cidadãos. De acordo com Florestan Fernandes (2008), a formação dos jovens deveria preparálos para construir uma sociedade democrática a partir de uma sociedade em transição. Para o sociólogo, as escolas deveriam desenvolver nos indivíduos atitudes coerentes com os ideais democráticos de personalidade e de existência social. A educação se tornou fundamental para a expansão da ordem social democrática, pois prepararia os cidadãos para a atuação responsável nos assuntos de interesse coletivo.

O fato é que construir uma sociedade plenamente democrática requeria a democratização da educação, que não se tornaria viável senão por uma reforma educacional em todos os níveis, em suas estruturas, no funcionamento e nos princípios pedagógicos. Para 
Florestan Fernandes (1971), a efetivação plena da democracia não seria possível nos moldes de uma sociedade capitalista, portanto, não se poderia esperar uma educação democratizada em sua plenitude no interior desse modo de produção. Contudo o intelectual admitia sem relutância que a sociedade de classes, livre e competitiva permitia às camadas populares conquistar terrenos na luta política e avançar nas conquistas sociais, dentre elas, o acesso à educação em todos os níveis. A ordem social livre competitiva, idealmente, visa à distribuição equitativa das condições e oportunidades essenciais para a disputa e conquista de posições na estrutura de poder e riqueza, o que abre um campo de disputa entre as forças sociais. Em termos da educação nacional, Florestan Fernandes defende que, "[...] embora esteja longe de possuir o sistema educacional de que carecemos, é preciso que nos habituemos a pensar na importância dele para o futuro da cidade”. (FERNANDES, 2008, p.282-283).

Segundo Florestan Fernandes (1966), o crescimento econômico e o desenvolvimento social não passariam de miragens, enquanto não se amparassem em um plano de reconstrução educacional. A elaboração de uma LDB alimentou a convicção do intelectual da possibilidade de intervenção racional e planejada na educação, em vista do desenvolvimento social e da democratização do conhecimento e da cultura. Seria a oportunidade de romper com as forças sociais da inércia e do conservantismo sociocultural que imperavam na sociedade brasileira e mantinham a educação como elemento de demora cultural.

A educação era entendida por Florestan Fernandes como um problema social, por isso se definia no terreno dos problemas práticos do ajustamento da herança cultural às condições materiais e morais viáveis da existência social de uma época. Em termos conceituais, o conjunto de coisas, encaradas socialmente como indesejáveis, e todas as atitudes que elas suscitam e os comportamentos inconformistas que desencadeiam, o sociólogo denomina de problema social. (FERNANDES, 1966). Para analisar as questões educacionais de seu tempo, Florestan Fernandes utilizou os conhecimentos teóricos do campo da sociologia aplicada. Em suma, esta é uma subdivisão da sociologia, que se ocupa do estudo de problemas sociológicos de interesse prático, por exemplo, os problemas educacionais, de ordem estrutural. Os estudos desse campo possuem como uma vantagem estender a elaboração teórica a temas e problemas que, por vezes, podem ficar entregues ao conhecimento de senso comum. A sociologia aplicada proporciona estender a explicação sociológica, levar a teoria aos problemas sociais práticos, cujas finalidades são a interferência e solução dos mesmos. Foi a partir desse campo do saber que Florestan Fernandes problematizou a educação brasileira e propôs a intervenção 
político-prática dos intelectuais naquilo que denominou de "dilema educacional brasileiro". (FERNANDES, 1971, p.194).

Isso implica dizer que os esforços políticos e intelectuais de Florestan Fernandes, na luta pela democratização da educação, tratam-se de um desdobramento da sua busca por alternativas que corroborassem a transição da ordem social senhorial-escravocrata (ou tradicional) à ordem social democrática. Expressão disso foi a sua inserção na Campanha no interior de um grupo de intelectuais e educadores de tendência majoritária liberal-burguesa. Florestan Fernandes se utilizou de todos os aparatos ideológicos que o grupo possuía para não só criticar o projeto de $\mathrm{LDB}$, mas indicar as suas possíveis repercussões posteriores. $\mathrm{Na}$ análise do sociólogo mencionado, a proposta educacional, contida no projeto de LDB, manteria o status quo educacional e ameaçaria os avanços sociais, decorrentes da transição.

Notamos que, para o intelectual, a defesa da educação pública tratava-se de uma reivindicação concreta, que não possuía fim em si mesma, mas um fim que se tornava meio para atingir algo maior, qual seja, "[...] criar condições dinâmicas essencialmente favoráveis à transição de uma ordem democrática incipiente para uma ordem democrática plenamente constituída". (FERNANDES, 2008, p.111-112). Avançar no processo de democratização da sociedade significava avançar na luta e na garantia de direitos sociais para os grupos sociais subalternos.

O envolvimento de Florestan Fernandes na Campanha se configurou como uma alternativa tática de tentar manobrar o movimento liberal-burguês em defesa da escola pública para fins progressistas. Lutar no interior de um grupo minimamente organizado em defesa da democratização da educação e apresentar as contradições existentes no discurso e na prática daqueles que defendem o modo de produção capitalista tratava-se de promover viabilidades práticas para os avanços da classe trabalhadora na luta de classes. Entendemos que essas considerações retratam o posicionamento assumido pelo intelectual ao longo de sua vida. Não fazia crítica esvaziada de conteúdo, os seus posicionamentos expressos em sua ação enquanto intelectual ancoravam-se em análises sobre a sociedade e a educação brasileira, sobre as quais desenhava reivindicações concretas para a realidade concreta.

\section{Para concluir ...}

Utilizamos da militância de Florestan Fernandes na luta em defesa da escola pública na década de 1960 para exemplificarmos uma possibilidade para os estudos sobre intelectuais 
na História da Educação. O substrato desses estudos pode ser o que chamamos de ação intelectual. Essa categoria se apresenta útil para as pesquisas pois acentua fatores que são objetivos na História da humanidade, 1) a ação dos intelectuais, que são sociais e históricas, por isso, práticas, 2) e a forma como esses intelectuais pensam e interpretam o mundo, expressa em suas teorias. Por serem objetivos, podemos apreender seus significados quando contextualizados no período histórico em que foram produzidos.

A História e a educação, são tributárias dos intelectuais e das suas intervenções políticas na realidade. Lucien Goldmann (1972) considera que o estudo da história global envolve o estudo da vida intelectual e consciente destes homens que a fizeram. Isso é possível, pois, segundo o autor, há um caráter estrutural no comportamento do intelectual, que aos estudiosos cabe revelar: quais as motivações histórico-sociais da obra de um intelectual? Nenhuma ação histórica e cultural do homem pode ser atribuída somente à libido, e ao comportamento libidinal. Toda produção e ação cultural é produto histórico, por isso motivada pelo social. É o social que nos permite explicar e compreender o sentido e a gênese de tudo que é histórico, inclusive, a obra de um intelectual, que é uma criação cultural. (GOLDMANN, 1972).

Não há dúvidas de que não há sociedade fora da ação dos indivíduos que a compõem, nem indivíduos estranhos a toda e qualquer vida social. Ante a isso, partimos do suposto que a ação intelectual é circunscrita por uma totalidade e deve ser considerada como resposta dos indivíduos aos problemas sociais de um determinado contexto. Os intelectuais não escrevem, socializam suas teorias e agem sobre a realidade por erudição ou diletantismo. Suas práticas sociais são sempre políticas, “[...] mesmo não tendo consciência clara das consequências políticas de seu trabalho intelectual, estes sujeitos não desempenham uma função inocente". (SCHLESENER, 2017, p. 216). Um intelectual é sempre um político, no sentido lato do termo, não importa se tenha clareza ou não de suas posições, pois elas repercutem nos movimentos da sociedade e atuam para conservar ou superar determinadas relações de hegemonia. (GRAMSCI, 2007). Por seu turno, suas obras assumem caráter político, pois, toda criação cultural "[...] é ao mesmo tempo um fenómeno individual e social, e insere-se nas duas estruturas constituídas pela personalidade do criador e o grupo social no qual foram elaboradas as categorias mentais que a estruturam". (GOLDMANN, 1972, p. 22). Ou seja, a obra dos intelectuais se inserem como ferramentas teóricas na disputa pela hegemonia. 
Nesse sentido, os textos publicados na imprensa (lançados ao grande público), conferências, palestras, discursos parlamentares, dentre outros textos que expressam o posicionamento político dos intelectuais diante de um problema social, passam a ser considerados fontes privilegiadas para as pesquisas em História da Educação. São esses textos que nos permitem apreender o intelectual em movimento, em ação, pois expressam seus posicionamentos, as suas ações políticas sobre o real, que são sociais, por isso práticas, ações dos homens sobre a base material.

Dessa forma, consideramos que tomar a ação intelectual como categoria para os estudos sobre os intelectuais na educação nos permite apreender e atribuir significados ao modo consciente de intervenção do intelectual na realidade, baseado em seu sistema teórico, haja vista que confere unidade ao pensamento e à ação do intelectual. A unidade entre teoria e prática do intelectual é um caminho adequado para os estudos no campo da História da Educação, em especial, na contemporaneidade. Na sociedade capitalista a consciência da totalidade social transindividual por parte dos indivíduos confere lugar a uma leitura de mundo parcial pautada em um individualismo exacerbado. Ante a visão parcial que se tem da realidade, o indivíduo se acha dividido em várias partes, o cidadão, o agente da vida econômica (o profissional), o indivíduo privado, e cada um destes setores possuem valores e regras de condutas diferentes.

Essa visão cindida dificulta interpretar os intelectuais a partir da unidade da sua vida e o desenvolvimento harmonioso de sua consciência sobre si e sobre a sociedade. A nós, essa visão dividida sobre os indivíduos, que por vezes pautam os estudos sobre os intelectuais, dificultam a criação de uma visão unitária do ser social e fortalece a tendência a considerá-lo ora como scholar, ora como erudito, ora como político (parlamentar), ora como ente familiar, sempre cindido e condicionados aos valores e às regras das instituições (ou dos institutos) sociais que dão diretrizes à tais papeis. Entendemos o indivíduo de modo unitário, por isso essas cisões não podem orientar os estudos sobre intelectuais, interpretando-os de diferentes formas segundo as regras dos diferentes espaços sociais, senão, por meio da ação intelectual, que nos permite compreender o desenvolvimento de sua consciência sobre o real e a sua intervenção na realidade referenciada no seu sistema teórico.

Nessa perspectiva, o estudo sobre um intelectual, seus posicionamentos e sua obra, reside no esforço de tornar a sua compreensão e significação acessível pelo esclarecimento dos traços gerais de sua ação intelectual, a qual só poderá ser compreendida na medida em 
que ela própria for inserida no estudo de uma estrutura social mais vasta, a totalidade. Não podemos perder de vista que "o homem é um ser histórico, material, que raciocina o mundo através de um conjunto de relações contraditórias que já existiam antes mesmo do seu nascimento. São as bases materiais da sociedade que afirmam aquilo que a sociedade é e não o universo das abstrações ideais". (LUCENA; LUCENA, 2017, p. 52). Por isso, só o funcionamento da sociedade e a inserção consciente do intelectual nesse movimento, pautada na sua teoria, poderá elucidar de modo objetivo as motivações e finalidades da ação social, prática, do indivíduo.

\section{Referências}

BORGES NETTO, M. A centralidade da educação na obra do intelectual Florestan Fernandes (1954-1964). 208f. Tese (Doutorado em Educação) - Universidade Estadual de Maringá. Maringá, 2016.

BUFFA, E. Ideologias em conflito: escola pública e escola privada. São Paulo: Cortez \& Moraes, 1979. (Coleção educação universitária).

FERNANDES, F. A condição de sociólogo. São Paulo: HUCITEC, 1978.

FERNANDES, F. A democratização do ensino. In: BARROS, R. S. M. de (Org.). Diretrizes e bases da educação nacional. São Paulo: Pioneira, 1960a.

FERNANDES, F. A sociologia numa era de revolução social. São Paulo: Editora Nacional, 1963.

FERNANDES, F. Educação e sociedade no Brasil. São Paulo: Dominus, 1966.

FERNANDES, F. Ensaios de Sociologia Geral e Aplicada. 2a ed. São Paulo: Pioneira, 1971.

FERNANDES, F. Mudanças sociais no Brasil. 4ª ed. São Paulo: Global, 2008.

FERNANDES, F. Objetivos da Campanha em Defesa da Escola Pública. In: BARROS, R. S. M. de (Org.). Diretrizes e bases da educação nacional. São Paulo: Pioneira, 1960b.

FERNANDES, F. Sociedade de classes e subdesenvolvimento. Rio de Janeiro: Zahar Editores, 1968.

GOLDMANN, L. Dialéctica e Ciências Humanas I. Tradução de João Arsênio Nunes. Lisboa: Editorial Presença, 1972.

GRAMSCI, A. Quaderni del carcere - Edizione critica dell'Istituto Gramsci. A cura di Valentino Gerratana. Turim: Einaudi, 2007, 4 vols. 
LUCENA, C.; LUCENA, L. Tudo o que está no ar só se explica quando é sólido. In. PREVITALI, F. S.; LUCENA, C.; LIMA, A. B. (Orgs). Desafios do trabalho e educação no século XXI. Uberlândia: Navegando Publicações, 2017.

MACHADO, M. C. G. Cenário atual das pesquisas sobre intelectuais em história da educação e suas interfaces. In. PINHEIRO, A. C. F.; CURY, C. E.; ANANIAS, M. (Orgs.). História da Educação Brasileira: experiências e peculiaridades. João Pessoa: EdUFPB, 2014, p.79-100.

MARX, K. Contribuições para a crítica da Economia Política. In. SADER, E.; JINKINGS, I. (Orgs.). As armas da crítica: antologia do pensamento de esquerda. São Paulo: Boitempo, 2012.

MARX, K. O 18 de Brumário de Luís Bonaparte. Tradução e notas de Nélio Schneider. São Paulo: Boitempo, 2011.

MARX, K.; ENGELS, F. A ideologia Alemã: crítica da mais recente filosofia alemã em seus representantes Feuerbach, B. Bauer e Stirner, e do socialismo alemão em seus diferentes profetas (1845-1846). Tradução de Rubens Enderle, Nélio Schneider e Luciano Cavini Martorano. São Paulo: Boitempo, 2007.

MATONTI, F.; SAPIRO, G. L'engagement des intellectuels: nouvelles perspectives. Actes de la recherche en sciences sociales, 2009, n.176-177, p.4-7.

SAVIANI, D. Florestan Fernandes e a educação. Estudos Avançados, São Paulo, v.10, n.26, p.71-87, jan.-abr. 1996.

SCHLESENER, A. H. A propósito da noção de intelectual que se pode intuir da noção gramsciana de "lorianismo". Revista Práxis e Hegemonia Popular, n.2, p.154-167, jun. 2017.

XAVIER, L. N. Particularidades de um campo disciplinar em consolidação: balanço do I Congresso Brasileiro de História da Educação (RJ, 2000). In: SOCIEDADE BRASILEIRA DE HISTÓRIA DA EDUCAÇÃO (Org.). Educação no Brasil. Campinas, SP: SBHE; Autores Associados, 2001, p. 217-234. 